\title{
Multiple Moderation Process of the Tail-Risk Hedging Managers
}

\author{
Joung Keun Cho \\ Institutional Advisory to QCAM Currency Asset Management AG, \\ U.S. Tax Advisory to Sellymon.com \\ Assistant Professor of Finance, School of Business, Seokyeong University, 714 \\ Hanlim Hall, 124 Seokyeong-ro, Seoul 02713, Korea \\ joungkec@alumni.cmu.edu
}

\begin{abstract}
One-month prior market momentum factor's mediation on the contemporaneous excess market return's effect on the current performance of certain hedge fund investment styles through one-month prior VIX level as the first moderator is moderated if the indirect effect of the one-month prior market momentum factor depends on the size of the returns of one-month prior VIX as the second moderator. This manuscript advances the literature by applying quantitative approaches to financial time-series by estimating and making inferences about the conditional process models with more than one moderator. We subsequently show how to test if a market risk factor's indirect effect on the returns of various hedge fund investment style is moderated by one variable when these two moderators are switching their primary and the secondary seats of dependency roles.
\end{abstract}

Keywords: Conditional moderated mediation effect, Indirect effect, Hedge fund investment style index

\section{Introduction}

Some hedge fund strategies appear to be earning risk premia through an economic function involving a way to transfer risk. Most hedge fund investment styles exhibit non-linear riskreturn payoffs as manifested through significant betas (or passive market exposure) on optionbased risk factors. For instance, the payoffs of event arbitrage, restructuring, event-driven, relative value arbitrage, and convertible arbitrage styles resemble that from writing a put option on the market index. This may be because these strategies lose money during the downturns in the equity market. It may also be the managers try calibrating a payoff profile similar to that from writing a put option to improve their Sharpe ratios or to assimilate to their incentive contract.

To be more specific, a fund manager has two types of skills; its stock selection and the market timing. The former is about the ability to select the right securities on a certain risk level and the latter is about the ability to forecast the potential market movement to adjust the risk-on positions on or before the right moment. It is generally conceived that hedge funds employing dynamic trading strategies have time-varying risky asset exposures to generate option-like return profiles. Since they are lightly regulated and more flexible to engage in leverage transactions based on their short-selling capacities and the derivative exposures, hedge funds are better positioned for factor timing than the rest of traditional money managers. Here, the

Article history:

Received (February 5, 2020), Review Result (March 13, 2020), Accepted (April 26, 2020) 
factor timing refers to the skill of a hedge fund manager to dynamically adjust the factor exposure for a specific factor based on a customized forecast of the conditioning information. Unlike traditional investment portfolio diversification at the asset-class level, factor-based investing involves identifying compensated factor exposures and constructing a portfolio by these factor allocations to harvest factor premia, rather than attempting to uncorrelated pure alpha (or the active manager skills). Measuring the true alpha of a hedge fund portfolio is one of the most frequently adopted methodology to identify active skillful manager, who may be able to repeat his/her performance going forward. Therefore, an accurate measure of alpha can only be obtained after isolating the manager skills by conditioning the risk premiums to which the portfolio is exposed.

Several studies adopted volatility conditioning information to evaluate the performance of active portfolios: Barroso and Santa-Clara [1] found that weighting cross-sectional equity momentum with its strategy volatility improves its risk-adjusted performance. Cho [2] tested various combinations of time-series convergence and divergence trades in KOSPI 200 futures market based on the statistical strength of the publicly available implied volatility index-based ("VKOSPI") trading signals out of the reconstructed entropy algorithms. Recently, Cho [3][4] studied the information contents of the VIX and the VKOSPI in global hedge fund index returns by applying global version of six equity risk factors and its potential diversification implications to Korean equity investors.

While Agarwal and Naik [5] show that some equity-biased hedge fund investment styles exhibit a relationship with option-based risk factors that consist of returns obtained by buying and selling one-month later liquid put and call options on the S\&P 500 index, we further distinguish between the level and the log returns in one-month prior volatility information to conditioning the dual moderation model as the primary and secondary moderators to one-month prior market momentum factor to mediate the contemporaneous excess market returns to the current excess performances of hedge fund styles. This design is practical in a way by combining both contemporary and one-month prior market risk factors in the same analysis. For instance, where excess returns of hedge fund-style indices and excess market returns are contemporaneous, all other systematic risk factors adopted such as market momentum $\left(W M L_{t-1}\right)$, the level $\left(V I X_{t-1}\right)$, and the size of return $\left(D V I X_{t-1}\right)$ information of the VIX are one-month prior. At the index level as the aggregates of individual hedge funds' net-of-fee returns, the results suggest that different hedge fund investment styles show ample variation in conditioning on the information of one-month prior implied volatility returns: Investment styles such as Emerging Market (EM), equity Long-Short (LS), Fund of hedge Funds (FoF), and Multi-Strategies (MS) show relatively more significant in conditioning on the contemporaneous excess market returns measured by the indirect (or mediated) effect of onemonth prior market momentums as moderated through the level and the size of one-month prior Chicago Board of Options Exchange implied volatilities versus other styles such as Global Macro (GM) and Commodity Trading Advisors (CTA).

The remainder of this article is structured as follows: The factor modeling in dual moderated mediation analysis, data analysis, and test results are presented in section 2, the statistical inferences on the indices of conditional and dual moderated mediations are discussed in section 3 , and section 4 concludes.

\section{Developing a dual moderated mediation factor model}

Any hedge fund index should represent a general proxy for some portion of the hedge fund industry. Due to the nature of private, lightly-regulated, offshore structure-favored hedge fund 
industry, hedge fund databases are subject to natural biases that militate against an accurate representation of hedge fund strategies and consequently distort performance. Certain biases do inflate performance while others may skew index performance downwards. Since the BarCap sub-indices may only be able to provide some biased snapshot of the 'true' hedge fund universe, they do not include defunct funds, thus do not account for the survivorship bias. Furthermore, these indices didn't explicitly account for the backfill and the incubation biases that arise due to the voluntary nature of self-reporting in hedge fund databases.

Exhibit 1 shows the summary statistics for five BarCap sub-indices from January 2003 to December 2016. While all five styles demonstrate positive annualized excess returns, the average Sharpe ratio (excess returns divided by realized volatility) across style indices varies from 1.14 (MS) to $0.41(\mathrm{FoF})$, due to FoF's lower annualized returns during the sample period versus other investment styles. All return distributions are leptokurtic mostly pronounced at MS (+9.98), and have negative skewness, except for GM (+0.25). Its cumulative return is seen in the right-hand panel of [Figure 1] that illustrates the hypothetical growth of $\$ 100$ invested in February 2003 in the respective style indices.

\begin{tabular}{lrrrrr}
\hline \multicolumn{1}{c}{ EM } & LS & FoF & GM & MS \\
\hline Total Return & $186.3 \%$ & $115.5 \%$ & $47.4 \%$ & $103.8 \%$ & $127.6 \%$ \\
Ann. Return & $7.8 \%$ & $5.6 \%$ & $2.8 \%$ & $5.2 \%$ & $6.0 \%$ \\
Ann. Volatility & $11.5 \%$ & $5.1 \%$ & $5.0 \%$ & $4.9 \%$ & $4.7 \%$ \\
- Gain Stdev & $6.5 \%$ & $2.7 \%$ & $2.2 \%$ & $3.4 \%$ & $2.4 \%$ \\
- Loss Stdev & $9.7 \%$ & $3.6 \%$ & $4.7 \%$ & $2.4 \%$ & $5.4 \%$ \\
Sharpe Ratio & 0.61 & 0.96 & 0.41 & 0.90 & 1.14 \\
Skewness & $(0.99)$ & $(0.71)$ & $(1.65)$ & 0.25 & $(2.45)$ \\
Exc. Kurtosis & 0.81 & $(2.06)$ & 2.33 & $(2.98)$ & 9.98 \\
Best Month Return & $11.1 \%$ & $3.8 \%$ & $3.0 \%$ & $4.4 \%$ & $3.9 \%$ \\
Worst Month Return & $-15.6 \%$ & $-4.9 \%$ & $-6.8 \%$ & $-3.3 \%$ & $-7.6 \%$ \\
\% Positive Months & $66.1 \%$ & $65.5 \%$ & $64.9 \%$ & $61.3 \%$ & $73.8 \%$ \\
Avg. Draw-Down & $-7.5 \%$ & $-2.0 \%$ & $-6.7 \%$ & $-4.5 \%$ & $-1.6 \%$ \\
Beta to S\&P 500 & 0.62 & 0.29 & 0.25 & 0.17 & 0.22 \\
Max Drawdown & $-42.5 \%$ & $-14.2 \%$ & $-23.2 \%$ & $-29.1 \%$ & $-19.3 \%$ \\
\hline
\end{tabular}

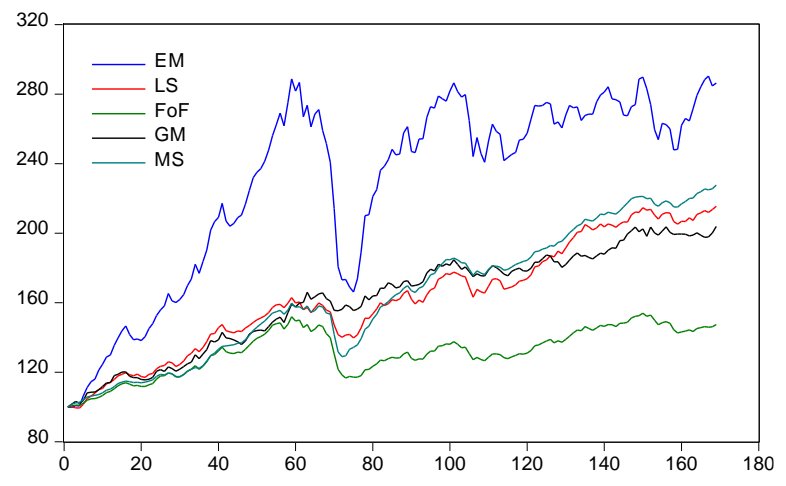

Figure 1. Summary Statistics for the BarCap Sub-Indices per Investment Style in the Sample

The average correlations of these BarCap style indices together with risk factors applied in dual moderated mediation modeling. The pair-wise correlation among the BarCap style indices are fairly high ranging between 0.72 and 0.92 , meaning that the style indices behave rather closely across strategies, so one may not expect a high degree of diversification benefits. While the correlations between the market excess return and the lagged market excess return risk factors is less than 0.2, the correlation between one-month prior level and the return of the VIX is less than 0.27 .

Recently, Cho and Kim [6] test for the market timing ability of Korean equity hedge funds by newly introducing the concept of style-tilting volatility (STV) as a measure to quantify the amount of variation or dispersion of a set of individual fund's style exposures. Their method implies that market timing ability results in a convex relation between individual fund returns and the various style as well as market factors. The analysis makes use of daily returns instead of typical hedge fund monthly returns to increase their statistical power (and the subsequent noise as well). The study evaluates the relationship between the three market-timing indicators such as STV, Volatility Timer, and Treynor-Mazuy type Market Timer, to the excess returns and Sharpe ratios of reclassified quintile hedge fund groups to identify those talented active style and volatility timers. Some hedge funds demonstrated enhanced risk-adjusted returns through a wider range of volatility timing behavior, while their active style bets did not necessarily result in persistent outperformance compared to the peer managers. 
Among Fama and French-type six global equity risk factors, this study adopts both contemporaneous and one-month prior market excess returns, one-month prior market momentum factor together with the VIX. Global factor definitions are consistent with a global market for risk, where hedge funds operate. The analysis here intentionally excluded the usual size (SMB), value (HML), quality (RMW), and conservativeness (CMA) factors in order to concentrate the interplay between and among contemporaneous market excess returns, onemonth prior market momentum, and the one-prior implied volatility dynamics.

Based on these empirical backgrounds, we now demonstrate the performance of a simple base case model. [Figure 2] presents the estimation results of our five-factor model estimated on all five BarCap sub-indices per investment style from January 2003 to December 2016, encompassing a couple of periods of market stress triggered by the U.S. sub-prime mortgage crisis and the fiscal crisis in the periphery Eurozone, offering sufficiently long data samples for a robust analysis of hedge fund returns. The regression of excess monthly hedge fund returns against five factors, per Equation (1). Each factor is defined as a monthly premium over the risk-free rate or as a long-short premium in case of $W M L_{t-1}$.

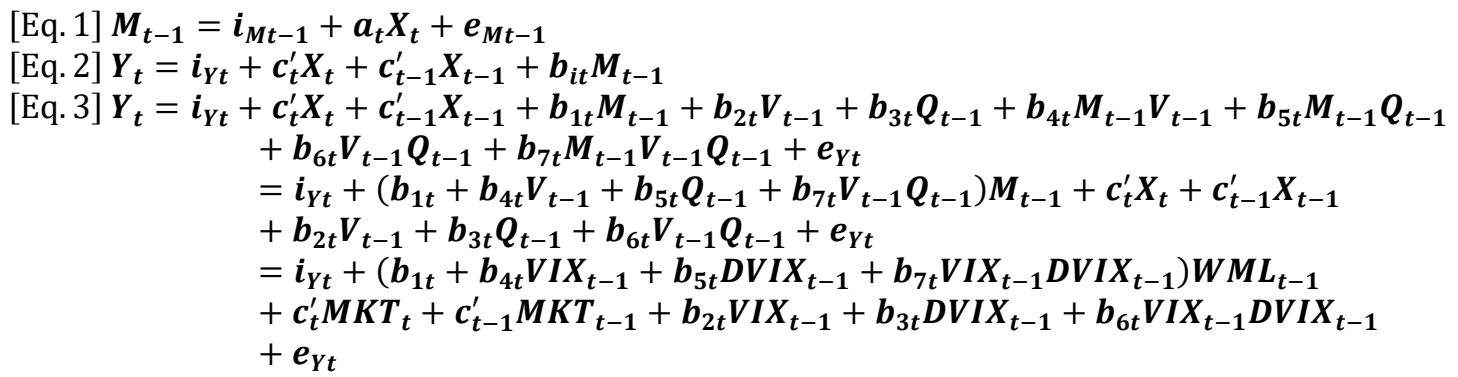

Figure 2. Dual moderated mediation model estimates

$Y_{t}$ is the monthly return for the BarCap hedge fund sub-indices in excess of the risk-free rate $\left(E M_{t}, L S_{t}, F o F_{t}, G M_{t}, M S_{t}\right), M_{t-1}$ is $W M L_{t-1}, X_{t}$ is $M K T_{t}, V_{t-1}$ is VIX $X_{t-1}, Q_{t-1}$ is $D V I X_{t-1}$. Risk free rate is the return of one-month Treasury bills, $M K T_{t}$ is the Fama-French global market return in excess of the risk free rate, $W M L_{t-1}$ is the one-month prior return of Fama-French global market momentum factor, VIX $X_{t-1}$ is the level of one-month prior CBOE implied volatility index as a primary moderator, and $D V I X_{t-1}$ is the return of one-month prior VIX (thus, return between $V I X_{t-1}$ and $V I X_{t-2}$ ) as a secondary moderator in this setting. The errors in Equation 2 and 3 for the estimation of $W M L_{t-1}$ and $Y_{t}$ assumed to be identically and independently distributed with means of zeros.

The direct effect of $M K T_{t}$ on $Y_{t}$ is estimated with $\boldsymbol{c}_{\boldsymbol{t}}^{\prime}$ in Equation 3, which quantifies how much two cases differing by one unit in $M K T_{t}$ are estimated to differ on $Y_{t}$, independent of the effect of $W M L_{t-1}$ on $Y_{t}$. In Equation 3, the effect of $Y_{t}$ on $W M L_{t-1}$ is unmoderated. Then, Equation 5 subsequently shows the combined effect $\left(\theta_{M_{t-1} \rightarrow Y_{t}}\right)$ of $W M L_{t-1}$ on $Y_{t}$. In Exhibit 2, the excess returns (or alphas) after controlling for the three-way interaction term or dual moderated mediation effects. While the only alpha of $\mathrm{FoF}_{t}$ index before the controlling of the dual moderated mediation effect in Exhibit 2 were significantly positive, the alphas of $L S_{t}$ and $M S_{t}$ sub-indices were become significantly positive at $5 \%$ level after controlling for the dual moderated mediation effects. On the other hand, the alpha of $F o F_{t}$ index after the controlling of the dual moderated mediation effect become insignificant. The dual moderated mediation effect nevertheless drives the $F o F_{t}$ alpha to be insignificant. This is another expression that the 
dual moderated mediation effect can explain the $F o F_{t}$ index and an illustration of the importance of double-layer fees in the space.

In terms of improvement in model fit, the BarCap $E M_{t}, L S_{t}, F o F_{t}$, and $M S_{t}$ sub-indices are statistically significant after the three-way interaction term is included. The incremental increase in $\mathrm{R}^{2}$ due to allowing the moderation of $X_{t}$ 's effect by $\left(W M L_{t-1} * V I X_{t-1} * D V I X_{t-1}\right)$ is $\Delta R^{2}=0.0073, \mathrm{~F}(1,157)=9.163, \mathrm{p}=0.0029$ for the BarCap $E M_{t}$ sub-index, $\Delta R^{2}=0.0040$, $\mathrm{F}(1,157)=3.688, \mathrm{p}=0.0566$ for $L S_{t}$ index, $\Delta R^{2}=0.0096, \mathrm{~F}(1,157)=7.935, \mathrm{p}=0.0055$ for $F o F_{t}$ index, $\Delta R^{2}=0.0008, \mathrm{~F}(1,157)=0.238, \mathrm{p}=0.625$ for $G M_{t}$ index, and $\Delta R^{2}=0.0136, \mathrm{~F}(1$, $157)=7.89, \mathrm{p}=0.0056$ for $M S_{t}$ index.

This is the same as the inference when framed instead as a test of (i) the improvement in model fit due to the three-way interaction terms when the sign of the log returns of one-month prior VIX differences in the indirect effect of the one-month prior market momentum factor appears to vary with the level of one-month prior VIX or (ii) the test of statistical significance as the regression coefficient of $\boldsymbol{a}_{\boldsymbol{t}} \boldsymbol{b}_{7 t} V I X_{t-1} D V I X_{t-1}$. A hypothesis test for $\boldsymbol{a}_{\boldsymbol{t}} \boldsymbol{b}_{7 t}$ VIX $X_{t-1}$ DVIX $X_{t-1}$ in the regression analysis is mathematically equivalent to this hypothesis test for $\Delta R^{2}$.

Since the covariance between one-month prior market momentum returns and one-month prior realized shocks measured by VIX as a reliable source of general market sentiment might be helpful to understand the contemporaneous hedge fund return profiles, it is intuitive whether the differences in the magnitude of indirect and partial effects might be able to explain more responsive managers within certain investment styles by tilting their risky asset exposures more dynamically in order to timely adjust their overall passive market exposures accordingly. Therefore, if any in-house a priori factor generating process shows a certain degree of unfavorable market momentum environment (or when $D V I X_{t-1}$ moves in a jump of $+2 \sigma$ ) at a high level of $V I X_{t-1}, F o F_{t}, M S_{t}$, and $G M_{t}$ investment style managers would tilt the fund's exposure to or from the momentum factor, under the influence of the simultaneous considerations of prior month's level and the returns of implied volatilities, which would reduce overall passive market exposures of their strategy returns, when we choose an appropriate market benchmark such as the S\&P 500 as the beta for equity-biased hedge fund styles.

If we test the market exposure of a strategy over time based on 36-month rolling regressions of market exposure, our dual moderation effect framework produces a more dynamic analysis of a strategy's beta over time. This type of analysis of passive market benchmark exposure vs. dual moderated mediation effect can be interesting because at the left-hand panel of Exhibit 8 plots the full dispersion of the BarCap EM strategy's beta exposures of the S\&P 500 against the dual moderated mediation effects. While investors tend to focus on net-of-fee returns of hedge fund styles, the panel displays a slight negative relationship (the slope of -0.0019) between the dual moderation effect and the excess returns of the S\&P 500 index. At both high positive and below-zero beta regions, this dual moderation effect remains to be in mostly negative territory, while remains mostly in positive at the betas in between. As Ang et al. [7] showed, the result of factor-tilting behavior with respect to dual moderation effect may change depending on the index chosen as a market benchmark, which doesn't make it possible to take into account the differences in risk exposures between the BarCap style indices and a market benchmark hindering any accurate measure of hedge fund managers' collective behavior of factor-timing.

\section{Conclusion}


For a money manager who believes the bullish market, it makes sense to tactically allocate to risky assets, and particularly building in high-beta trading positions, as they are likely to benefit most out of rising market. It should be the other way round when it comes to a bearish view. According to this reasoning, an overconfident market timer might actively exploit the general market sentiment of risk preference as represented by the implied equity market volatilities.

This paper applied the concept of conditional and the moderation of moderated mediation to hedge fund return time-series. $V I X_{t-1}$ conditionally moderates the mediation of $M K T_{t}{ }^{\prime} \mathrm{s}$ effect on $Y_{t}$ through $W M L_{t-1}$ if the size of the indirect effect of $M K T_{t}$ is related to $V I X_{t-1}$ conditioned on a specific value of a second moderator $D V I X_{t-1}$. The moderation of $M K T_{t}{ }^{\prime} \mathrm{s}$ indirect effect by $V I X_{t-1}$ is moderated by $D V I X_{t-1}$ if DVIX $x_{t-1}$ is related to the rate of change of the indirect effect of $M K T_{t}$ as $V I X_{t-1}$ changes.

In fact, from Exhibit 4, the regression coefficient of the three-way interaction of the BarCap $G M_{t}$ sub-index is statistically not different from zero and as can be seen in Exhibit 6, the coefficient of $\boldsymbol{a}_{\boldsymbol{t}} \boldsymbol{b}_{7 t} V I X_{t-1} D V I X_{t-1}$ is basically nil that it is less meaningful to interpret the $G M_{t}$ 's indirect effect with respect to dual moderators in this analysis. In cases of the BarCap $E M_{t}, L S_{t}, F o F_{t}$, and $M S_{t}$ sub-indices, the coefficients of $\boldsymbol{a}_{t} \boldsymbol{b}_{7 t} V I X_{t-1} D V I X_{t-1}$ are small negatives but all statistically different from zero. Again, for the BarCap $G M_{t}$ sub-index, the moderation of the indirect effect of contemporaneous excess market returns by one-month prior VIX level do not differ between the size of the one-month prior VIX returns.

\section{Acknowledgements}

We thank the anonymous reviewers for their careful reading of our manuscript and their many insightful comments and suggestions. We also thank Mr. Sebastian Schaefer, Managing Partner and Founder of Green Shoots Group of Companies, Mr. Hans Kim, Founding Partner of Green Shoots Capital Solutions Korea L.L.P., Mr. Byung Ki Han, C.E.O. of Trinity Asset Management, Mr. Seon Goo Lee, C.E.O. of Sellymon.com, the most comprehensive Korean and the U.S. tax information online platform, and Ms. Karen Jo from Landmark Asset Management in Seoul for their discussion and support for the development of the alternative investment solutions for the qualified Korean institutional and private investors since November 2016. Some part of the elaboration is based upon various insightful inputs from these gentlemen, but any error remains solely responsible to the author of this article. This Research was supported by Seokyeong University in 2020 and also the part of output of the Executive Asset Management Advisory Project between Simone Investment Managers and Seokyeong University.

\section{References}

[1] Barroso P. and P. Santa-Clara., "Momentum has its moments." Journal of Financial Economics, vol.116, no.1, pp.111-120, (2015) 10.1016/j.jfineco.2014.11.010,

[2] Cho J.K., "Information content of the VKOSPI entropy indicator - a dynamic asset allocation approach." International Information Interdisciplinary Journal, vol.20, no.7(B), July, (2017)

[3] Cho J.K., "Implied equity volatility and liquid alternative hedge fund investing by qualified Korean investors." International Information Interdisciplinary Journal, vol.20, no.10(B), October, (2017)

[4] Cho J.K., "Qualified Korean investors' liquid alternative global hedge fund investing under autocorrelation effects.” Journal of Economic Studies (Korean), vol.35, no.2, May, (2017)

[5] Agarwal V. and Naik, N.Y. "Risk and portfolio decisions involving hedge funds." Review of Financial Studies, vol.17, no.1, pp.63-98, (2004) DOI: 10.1093/rfs/hhg044 
[6] Cho J.K. and Kim, G.W., "Making a bet at a right time: style and volatility timing abilities of Korean equity hedge funds." Asset Management Review, vol.5, no.2, December, http://hdl.handle.net/10203/241118, (2017)

[7] Ang A., Hodrick R.J., Xing Y., and Zhang X., "High idiosyncratic volatility and low returns: international and further U.S. evidence.” Journal of Financial Economics, vol.91, no.1, pp.1-23, (2009) DOI: 10.3386/w13739 
Multiple Moderation Process of the Tail-Risk Hedging Managers

This page is empty by intention. 